\title{
Finger Skin Temperature and Laser-Doppler Finger Blood Flow in Subjects Exposed to Hand-Arm Vibration
}

\author{
Seyed Mohammad MIRBOD ${ }^{1 *}$, Hideyo YOSHIDA ${ }^{2}$, Marjan JAMALI ${ }^{3}$, \\ Kazuhisa MIYASHITA ${ }^{4}$, Haruko TAKADA ${ }^{1}$, Ryoich INABA ${ }^{1}$ and Hirotoshi IWATA ${ }^{1}$ \\ ' Department of Hygiene, Gifu University School of Medicine, 40, Tsukasa-Machi, Gifu 500-8705, Japan \\ ${ }^{2}$ Department of Epidemiology, Tokyo Metropolitan Institute of Gerontology, 35-2 Sakae-cho, Itabashi-ku, Tokyo \\ 173-0015, Japan \\ ${ }^{3} 1$ st Department of Anatomy, Gifu University School of Medicine, Gifu, Japan \\ ${ }^{4}$ Department of Hygiene, Wakayama Medical College, Kyubancho 27, Wakayama 640-8155, Japan
}

Received December 3, 1997 and accepted February 4, 1998

\begin{abstract}
Objectives; This study was aimed to assess the peripheral circulatory functions of forestry workers exposed to hand-arm vibration, using simultaneous measurements of finger skin temperature (FST) and finger blood flow (FBF). Methods; The subjects were five men with vibration-induced white finger (VWF), four subjects with numbness in their hands and five exposed controls without any signs or symptoms related to vibration syndrome. Simultaneous measurements of FST and laserDoppler FBF were performed before, during and following a 10-min recovery period after the hand was immersed in cold water $\left(10^{\circ} \mathrm{C}, 10 \mathrm{~min}\right)$. Partitional measurements of finger blood flows could be made between the capillaries and deeply located vessels using two laser-Doppler flow probes having narrower and wider optic fiber separations. Results; The FST as well as the FBF of the capillary and deeply located vessels during and following the cold immersion test in those with VWF and in the subjects with numbness had a slight increase immediately following the cold immersion and no tendency to be augmented as the time span increased. After the cold immersion test, the control group had significantly greater FST and FBF compared to other groups. Particularly, from the 5th to the 10th min after the cold provocation, the values of FBF of the deeply located vessels in those with VWF were significantly lower than the controls. During the course of observation, the FST had significantly linear relationship with the recorded capillary and deep FBF values, and that was much closely correlated with the deep FBF (i.e., $P<0.01$ in each selected condition). The slope of the regression lines in the capillary were steeper and shallow in the deep FBF. Conclusions; In addition to the measurement of capillary FBF, more detailed and accurate information on the peripheral circulatory functions of vibration-exposed subjects can be obtained by including the assessment of the deep FBF.
\end{abstract}

Key words: Hand-arm vibration, Finger skin temperature, Laser-Doppler blood flow, Cold provocation, Correlation

\section{Introduction}

Exposure to occupational vibration can be the cause of different symptoms in the hands and arms. These symptoms-

*To whom correspondence should be addressed. circulatory disturbances in the fingers, paraesthesias of the hands and arms, degeneration of the bones and joints, and diminished muscle force-comprise a complex known as hand-arm vibration syndrome (HAVS) ${ }^{1,2)}$. The best documented symptom is the periodic circulatory disturbances in the fingers- - that is, vibration-induced white finger (VWF). 
Many objective tests have been developed to detect circulatory impairment in the fingers of vibration-exposed workers. Measurement of finger skin temperature (FST) in combination with local cooling of the hand in order to stimulate vasoconstriction is most often used in the surveys of vibration syndrome. In the last few years, measurement of finger systolic pressure has gained increasing importance as it seems to be of high diagnostic value ${ }^{3,4)}$.

In recent years, a new, noninvasive technique-laser-Doppler blood flowmetry (LDBF) - has been proposed for the measurement of finger blood flow (FBF) to surface tissue ${ }^{5,6}$. Cutaneus LDBF enables monitoring of changes in skin perfusion by quantifying the phase shift of laser light induced by moving red blood cells under a fiber optic probe. It thus can identify the presence of and response to a vasoconstrictive stimulus such as cold water immersion test. It has also been suggested that LDBF could measure changes in FBF through the vessels at different depths by changing the distance between the exciting and receiving optic fiber probes $^{7-9}$. Studies on the finger capillary together with the deeply located vessels (mostly arteriovenous shunts) have been conducted in healthy subjects ${ }^{8)}$ and in subjects suffering from primary Raynaud's phenomenon ${ }^{10)}$.

The technique of capillary LDBF has been applied in some vibration-related investigations. Exposure to hand-arm vibration has been reported to reduce the capillary FBF in healthy subject ${ }^{11}$. Some researchers have found the reduction to be greater in men with the symptoms related to HAVS ${ }^{12)}$ than in healthy controls but others have not ${ }^{13)}$. However, to our knowledge the assessment of both capillary and deep FBF has not been reported in subjects using hand-held vibrating tools.

The present study was undertaken to evaluate the peripheral circulatory functions of three groups of chain saw operators by using the simultaneous measurements of FST and capillary as well as deep FBF before, during and following a cold provocation test. The underlying concept for the simultaneous measurements of FST and FBF is that surface temperature at the fingertip is essentially depending on circulation and therefore is able to reflect the volume of peripheral blood flow in an indirect but reliable manner ${ }^{14)}$.

\section{Subjects and Methods}

This survey was conducted among male chain saw operators working on private forestry enterprises in northern part of Gifu Prefecture, Japan. The study was carried out in connection with the compulsory health examination which stipulate special medical examination for vibration exposed workers ${ }^{15)}$. According to the results of the questionnaire, health examinations and the subjects' medical history, VWF was confirmed in five out of 67 subjects. All these five subjects suffered from numbness and pain in their hands, as well, and they were considered as the "VWF" group. From the rest of chain saw operators 4 persons with numbness in their hands, and 5 subjects without any signs or symptoms related to HAVS were selected and were considered as the "numbness" and "control" groups. They were matched for age and exposure duration. The characteristics of the three groups are shown in Table 1.

The Stockholm Workshop scale for the peripheral ${ }^{16)}$ and sensory reduction ${ }^{17}$, and the method of scoring finger blanching ${ }^{18)}$ were used for further evaluation of the subjects with VWF and/or numbness. The duration of the symptoms and the latency of VWF (the time before the onset of finger blanching) were also documented.

\section{Finger skin temperature and finger blood flow}

All measurements were made at a quiet-air-conditioned room $\left(24 \pm 1^{\circ} \mathrm{C}\right)$ on lightly clad seated subjects. During the tests, the subjects were not allowed to talk or move. Smoking and exercise were avoided for at least $1 \mathrm{~h}$ before the tests. For each subject $30 \mathrm{~min}$ was allowed for equilibration to room temperature. The FST was taken by a thermistor

Table 1. The mean $\pm S E M$ of the three groups' characteristics

\begin{tabular}{lccc}
\hline Characteristics & $\begin{array}{c}\text { VWF } \\
(\mathrm{n}=5)\end{array}$ & $\begin{array}{c}\text { Numbness } \\
(\mathrm{n}=4)\end{array}$ & $\begin{array}{c}\text { Control } \\
(\mathrm{n}=5)\end{array}$ \\
\hline Age (years) & $58.0 \pm 2.9$ & $61.2 \pm 1.5$ & $58.8 \pm 3.0$ \\
& $(51-66)$ & $(57-64)$ & $(48-64)$ \\
Systolic blood & $128.4 \pm 5.5$ & $135 \pm 1.9$ & $140.4 \pm 5.1$ \\
pressure (mm Hg) & $(110-140)$ & $(130-138)$ & $(122-150)$ \\
Diastolic blood & $75.2 \pm 4.0$ & $82.0 \pm 2.9$ & $80.0 \pm 2.9$ \\
pressure (mm Hg) & $(64-86)$ & $(76-90)$ & $(72-90)$ \\
Exposure (years) & $25.0 \pm 3.7$ & $28.7 \pm 4.2$ & $21.6 \pm 3.7$ \\
& $(13-35)$ & $(20-40)$ & $(11-34)$ \\
Daily vibration & $5.4 \pm 0.4$ & $4.7 \pm 0.6$ & $3.6 \pm 0.9$ \\
exposure (hours/day) & $(4-6)$ & $(3-6)$ & $(1-6)$ \\
Chain saw usage & $90.0 \pm 25.2$ & $52.5 \pm 8.5$ & $56.0 \pm 15.0$ \\
$\quad$ days/year) & $(30-150)$ & $(30-70)$ & $(20-100)$ \\
Bush cutter usage & $84.0 \pm 19.6$ & $85.0 \pm 19.3$ & $44.0 \pm 27.7$ \\
$\quad$ days/year) & $(20-130)$ & $(30-120)$ & $(20-130)$ \\
Total working days & $200.0 \pm 30.6$ & $197.5 \pm 23.2$ & $220.0 \pm 30.3$ \\
(days/year) & $(80-250)$ & $(150-260)$ & $(120-300)$ \\
\hline
\end{tabular}

The ranges are shown in the parenthesis.

(No significant differences among the groups could be obtained.) 
(Takara Thermistor D-925) attached to the subject's most severely affected finger; if all were equally affected then the middle finger was used. Measurements were made on the corresponding fingers of the "control" and "numbness" groups.

The FBF was measured by the laser Doppler flowmeter, ALF 21 (Advance Co, Tokyo, Japan). The equipment had a low power $(2 \mathrm{~mW})$ semiconductor laser source, producing light at $780 \mathrm{~nm}$ wavelength. The probes used here had fiber separations between exciting and receiving fibers of 0.3 (LDF-0.3) and $0.7 \mathrm{~mm}$ (LDF-0.7). The maximum sensitivities for LDF-0.3 and LDF-0.7 have been reported to be at depths of 0.8 and $1.2 \mathrm{~mm}$ from the tissue surface, respectively ${ }^{8)}$. According to Hirata et al. ${ }^{8}$, using flow probes with different optic fiber separations, as applied in this survey, could measure partitional blood flow through superficial vessels, predominantly capillaries, and deeper vessels, mainly arteriovenous shunts, in the human finger. Hence, in order to simultaneously record the capillary and deep FBF, the back scattered light was led by a twin optic fiber to two sets of the ALF 21. The output signals from the flowmeters were continuously recorded on paper with double-pen recorder (U-228-2P Pantos, Nippon Denshi Kagaku, Kyoto, Japan). Values of tissue blood flow were expressed in $\mathrm{ml}$ $\mathrm{blood} / \mathrm{min} / 100 \mathrm{~g}$ tissue.

The tissue probe of the laser-Doppler flowmeter was lightly attached to the skin of the finger (i.e., the same finger which was selected for the measurement of FST) with a circular, open-centered, double-sided adhesive tape of the same diameter. A baseline flow was decided when a steady baseline reading was achieved. Then, the hand was gently immersed in cold water $\left(10^{\circ} \mathrm{C}\right)$ and the flows were recorded during a 10 -min cold provocation test and in a period of $10-\mathrm{min}$ after immersion. According to the manufacturer's recommendations, the exact values of deep FBF could be obtained using the following equation:

$$
\left(\mathrm{F}_{2} / \mathrm{F}_{1}\right)=\left\{\left(\mathrm{F}_{\mathrm{w}} / \mathrm{F}_{\mathrm{s}}\right)-0.7\right\} / 0.3
$$

where

$$
\begin{gathered}
\mathrm{F} 1=\mathrm{F}_{\mathrm{s}}: \text { recorded values of capillary FBF measured by } \\
\text { the narrower probe (LDF-0.3), } \\
\mathrm{F}_{\mathrm{w}}: \text { recorded values of deep FBF measured by the } \\
\text { wider probe (LDF-0.7), } \\
\mathrm{F}_{2}: \text { exact value of deep FBF. }
\end{gathered}
$$

\section{Statistical methods}

The data were entered into a computer for statistical analysis, using Statistical Package for Social Sciences (SPSS,
Inc., Release 6.0, 1993) and StatView (Abacus Concepts, Inc. Release 4.0,1993). The descriptive statistics were used to determine means, standard errors of means (SEM), and the ranges of various determinants. One way analysis of variance (ANOVA) was used to test the null hypothesis of no difference in the mean values of each factor among the three groups. The multiple comparison tests were conducted using the Tukey's honestly significant difference (Tukey's HSD) and the Scheffé methods for the equal and unequal sample sizes, respectively ${ }^{19)}$. The correlation coefficients were also computed. The significant level was taken as $P<0.05$.

\section{Results}

The outline of disorders in the "VWF" and "numbness" groups are shown in Table 2. Two subjects with VWF were in the stage 2 (moderate) and 3 of them were recognized to be in the stage 3 (sever) of the Stockholm Workshop scale. The subjects in both groups were in the stage $2 \mathrm{SN}$ of sensory disturbance for the right and left hands. The score of finger blanching on the left hand was slightly higher than on the right hand. Both groups showed a comparable value for the duration of numbness in their hands.

The initial FST of those in the "numbness" group was

\begin{tabular}{|c|c|c|}
\hline $\begin{array}{l}\text { Disorder } \\
\text { outline }\end{array}$ & $\begin{array}{l}\text { VWF } \\
(n=5)\end{array}$ & $\begin{array}{c}\text { Numbness } \\
\quad(n=4)\end{array}$ \\
\hline $\begin{array}{l}\text { Duration of VWF } \\
\text { (years) }\end{array}$ & $\begin{array}{c}6.8 \pm 1.6 \\
(3-10)\end{array}$ & - \\
\hline $\begin{array}{l}\text { Latency of VWF } \\
\text { (years) }\end{array}$ & $\begin{array}{c}18.2 \pm 4.9 \\
(7-32)\end{array}$ & - \\
\hline $\begin{array}{l}\text { Score of finger } \\
\text { blanching (right) }\end{array}$ & $\begin{array}{c}11.6 \pm 4.1 \\
(5-24)\end{array}$ & - \\
\hline $\begin{array}{l}\text { Score of finger } \\
\text { blanching (left) }\end{array}$ & $\begin{array}{c}13.2 \pm 5.7 \\
(5-33)\end{array}$ & - \\
\hline $\begin{array}{l}\text { Stage of VWF } \\
\text { [n (stage)] }\end{array}$ & $2(2), 3(3)$ & \\
\hline $\begin{array}{l}\text { Stage of sensory } \\
\text { reduction }(n)\end{array}$ & $2 \mathrm{SN}(5)$ & $2 \mathrm{SN}(4)$ \\
\hline $\begin{array}{l}\text { Duration of numbness } \\
\text { (years) }\end{array}$ & $\begin{array}{l}7.4 \pm 1.2 \\
(4-10)\end{array}$ & $\begin{array}{c}7.0 \pm 1.1 \\
(5-10)\end{array}$ \\
\hline $\begin{array}{l}\text { Subjects with } \\
\text { pain in the hands }\end{array}$ & 5 & - \\
\hline
\end{tabular}
lower compared with other subjects; however no significant differences could be obtained. At the $1 \mathrm{st}$ min during the cold provocation test, a vasoconstriction in all subjects was

Table 2. Subjects' disorders outline in the "VWF" and "numbness" groups

Values are shown as means \pm SEM and ranges. 
noticed. The recorded values of FST in the "VWF" and "numbness" groups were similar over a period of 10-min following the cold immersion test. Compared with these two groups, the "control" group tended to have recovery in their FST from the third min after removal of the hand from the cold water. Multiple comparison analysis showed significant differences in the mean values of FST of the control group compared to the "VWF" and "numbness" groups from the 8th to the 10th min after the cold immersion test.

Figures 1 and 2 show the mean $( \pm$ SEM) capillary (LDF0.3 ) and deep (LDF-0.7) FBF for the three groups. In all

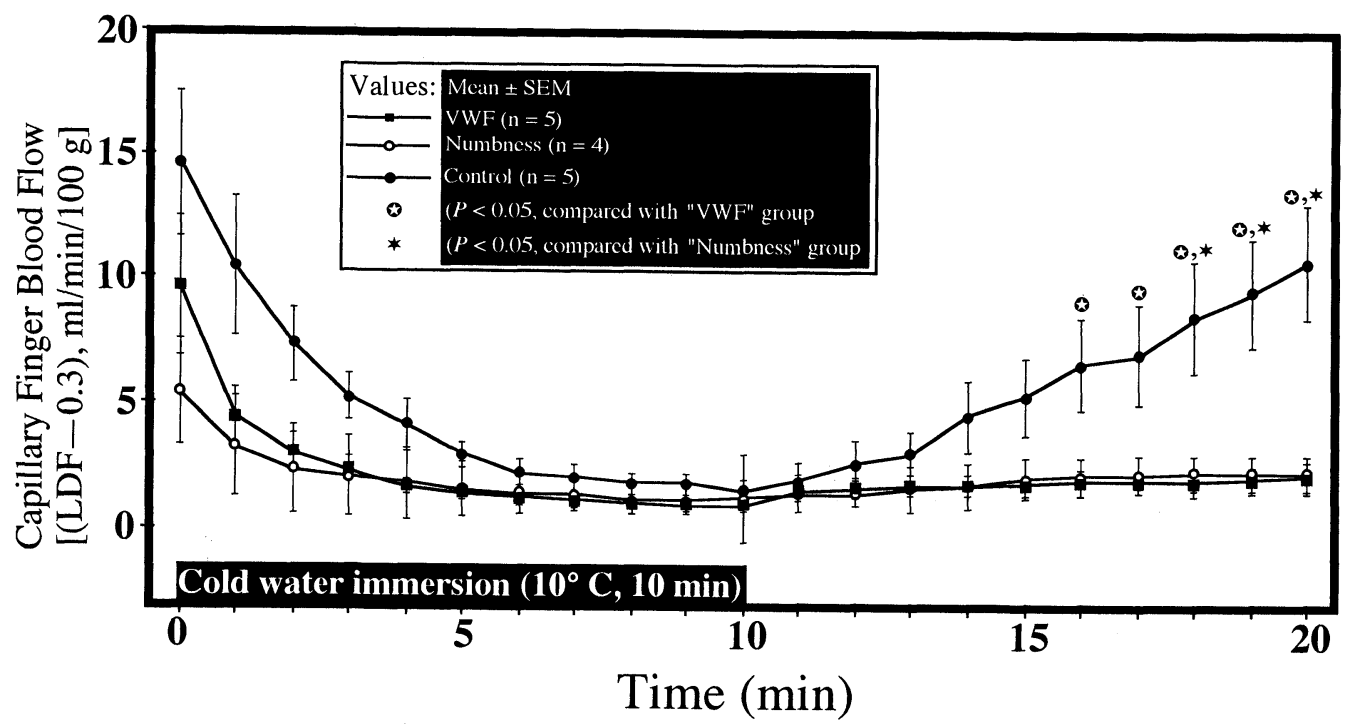

Fig. 1. The capillary finger blood flow (LDF-0.3, probe having the optic fiber distance of $0.3 \mathrm{~mm}$ ) of the three groups of forestry workers before, during and following the cold immersion test The significant differences are also shown.

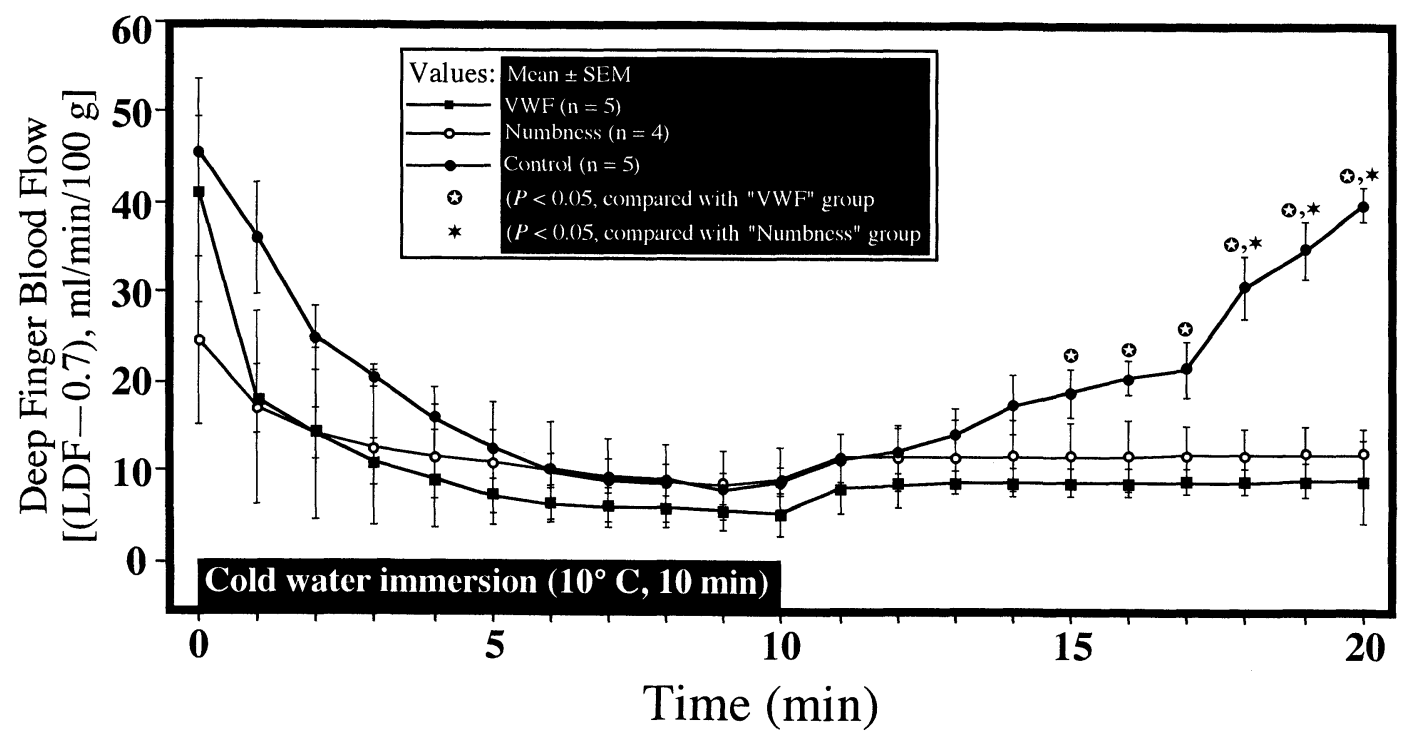

Fig. 2. The deep finger blood flow (LDF-0.7, probe having the optic fiber distance of $0.7 \mathrm{~mm}$ ) of the three groups of forestry workers before, during and following the cold immersion test The significant differences are also shown. 
subjects, the total amount of blood passing through the capillaries were smaller than through the deeply located vessels before, during and after the cold immersion test. When the fingers were warm (room temperature), the capillary and deep FBF of the subjects suffering from numbness were even lower than those with VWF. At the 1 st min during the immersion test, the decrease in mean capillary FBF was $54 \%$ in subjects with VWF; $40 \%$ in the "numbness" group; and $29 \%$ in the "control" group. The capillary FBF of the subjects with VWF and those with numbness had a slight recovery at the 1 st min after the immersion and afterwards it did not tend to increase and remained below $2.5 \mathrm{ml} / \mathrm{min} / 100 \mathrm{~g}$ over a period of $10-\mathrm{min}$ after immersion. The significant differences in the mean capillary FBF of the three groups following the cold immersion test are shown in Figure 1.

The mean deep FBF after equilibration at room temperature recorded for the "VWF" group $(41.5 \pm 12.3 \mathrm{ml} / \mathrm{min} / 100 \mathrm{~g})$ was comparable to the "control" group $(45.9 \pm 4.0 \mathrm{ml} / \mathrm{min} /$ $100 \mathrm{~g})$ and greater than the "numbness" group (24.9 \pm 9.4 $\mathrm{ml} / \mathrm{min} / 100 \mathrm{~g}$ ). When the hand was immersed in the cold water, the deep FBF in the subjects with VWF and those with numbness went below $20 \mathrm{ml} / \mathrm{min} / 100 \mathrm{~g}$, while the recorded mean value in the control group was about $36 \mathrm{ml} /$ $\mathrm{min} / 100 \mathrm{~g}$. During the cold immersion test, the deep FBF of those with VWF was gradually decreasing and reduced to level of below $6 \mathrm{ml} / \mathrm{min} / 100 \mathrm{~g}$ at the end of the cold immersion test. After removal of the hand from cold water, the patterns of deep FBF in the three groups were very similar to those obtained for their capillary FBF. The results of multiple comparison tests in the mean values of deep FBF of the three groups are shown in Figure 2.

It should be noted that among the subjects' characteristics, their daily working time ( $h$ /day) had an inverse significant correlation (age adjusted) with the deep FBF recorded for total subjects $(n=14)$ from the 7 th to the 10th min after the hand immersion $(\mathrm{r}=-0.60, P<0.05)$.

The linear relationships between the values of FST and the capillary as well as the deep FBF before, at the 5th and 10 th min during the immersion, and at the 5 th and 10th min after removal of the hand from cold water were obtained in total subjects ( $\mathrm{n}=14$ for each calculation). The results are shown in Figure 3. In each condition, the FST values had significantly linear relationships with the recorded capillary and deep FBF values, and that was much closely correlated with deep FBF (i.e., $P<0.01$ in all conditions). The slope of the regression lines in the capillary were steeper and shallow in the deep FBF, except at the 10th min after immersion.

\section{Discussion}

Before evaluating the results obtained, the complex structure of the skin vascular bed must be addressed, specially the microcirculation. The fingertips have a dual circulation consisting of capillaries and arteriouvenous shunts. The capillary blood flow is designated as nutritional blood flow. The arteriouvenous shunts are communications between small arteries or arterioles and the corresponding venous channels. They are specially numerous in the human fingernail bed and in the fingertip. They play a role in temperature regulation of the digits and of the body by increasing or decreasing the radiation of heat. The arteriouvenous shunts are believed to be primarily controlled by the sympathetic nervous system, constricting during stimulation and dilating during withdrawal of sympathetic stimuli ${ }^{20,21)}$.

Hitherto, in Japan, for the evaluation of peripheral circulatory functions in workers exposed to vibration two tests of FST and nail compression on the fingers have generally been used. The FST has been widely performed with different procedures; however, a standard method has not been established yet. As for the nail compression test, the disadvantage of variations in results due to the examiner's skill and experience should be noted. In this investigation, the simultaneous measurement of FST and dual FBF were used to evaluate peripheral disturbances in forestry workers.

Because the chain saw operators all work in cold and exposed condition during the winter, in the present study the controls were recruited from men who experienced similar working conditions. Objective testing employed here showed that the disorders related to HAVS were more pronounced in the subjects with VWF. A true incidence or pattern of severity cannot of course be determined from such a small sample, however, economic constraints on the forestry service did not permit a larger number of workers to be studied. It was only possible to study each man on one occasion, so the severity of vasospasm was tested in only one finger of each hand to allow time for the other subjects.

We demonstrated that the patterns of the capillary and deep FBF during and following the cold immersion test in those with VWF and subjects with numbness were quite comparable - a slight increase immediately after cold immersion and no tendency to be augmented as the time span increased. It has been reported that hand-arm vibration induces a decrease in blood flow in normal fingers ${ }^{11)}$ and this vasoconstrictor response seems to be augmented in some subjects with $\mathrm{VWF}^{12}$. However, it is uncertain if the 

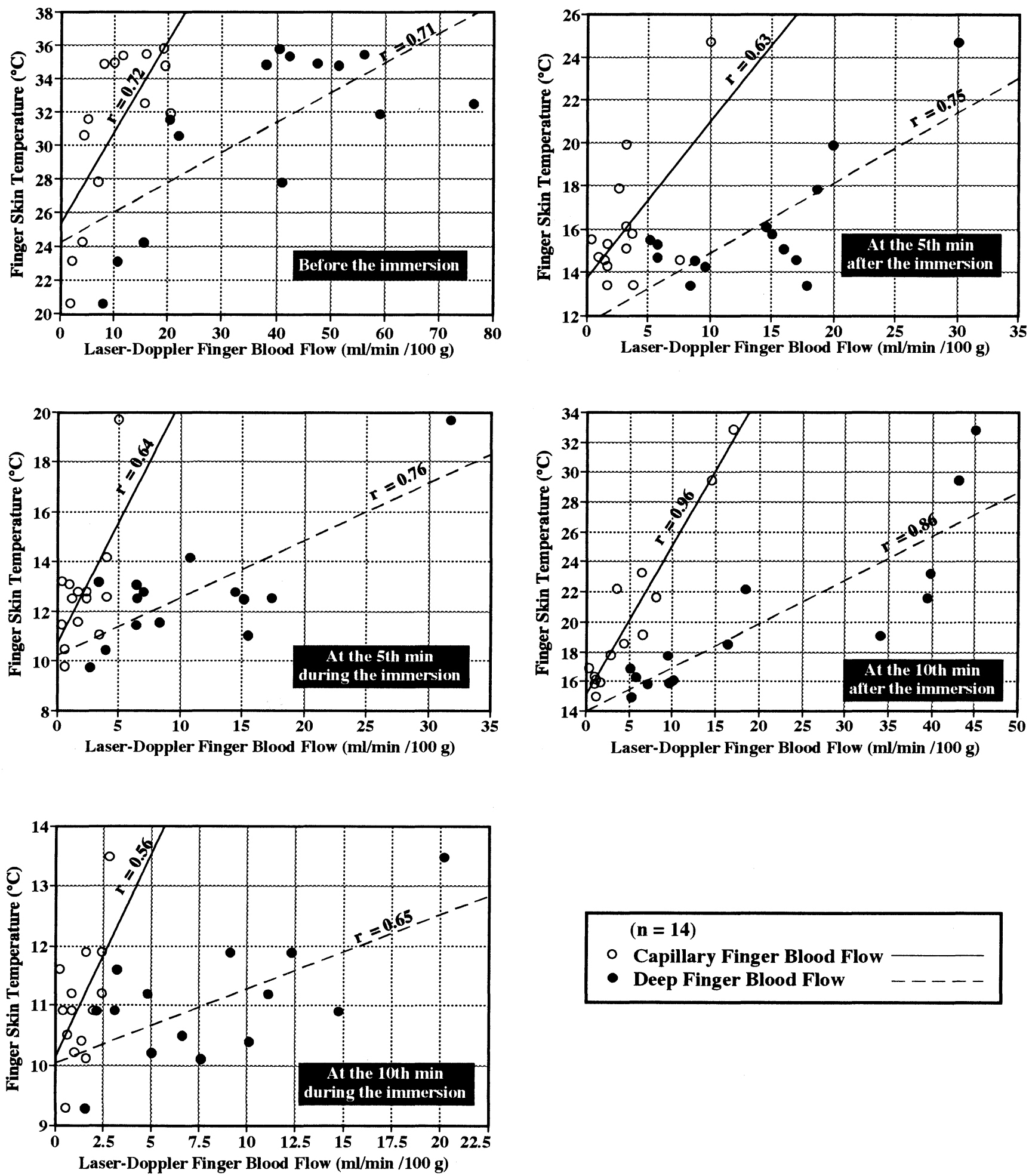

$(n=14)$

- Capillary Finger Blood Flow

- Deep Finger Blood Flow

Fig. 3. Relationships between finger skin temperature and the capillary as well as the deep finger blood flows obtained before, during and following the cold immersion test

The regression lines are shown for total subjects. 
vasoconstriction is due to a local or a central reflex mechanism ${ }^{11,12)}$. Okada et al. ${ }^{22)}$ found the fingertip blood flow to be significantly lower in vibration-exposed groups compared with a control group. By arteriography James and Galloway ${ }^{23)}$ found that subjects with severe VWF showed definite evidence of occlusions in the hand and digital arteries, and in nearly all fingers the presence of arterial occlusion coincided with the reporting of "white finger." In our subjects, the occupational vibration exposure was due to the use of chain saws and bush cutters. The hand-arm vibration exposure in these subjects was previously reported ${ }^{24)}$ to be $2.7-5.1 \mathrm{~m} / \mathrm{s}^{2}$. The contributing factors which might be attributed to the consequence of hand-arm vibration on the FBF could be summarized as follows: (1) the effects of handle grasping power, that is the reduction in peripheral circulation induced by the mechanical compression of the skin vascular bed; (2) the effects of sustained muscle exertion (i.e. lifting and holding a chain saw during operation); (3) direct effects of local vibration transmitted from the handle of a chain saw to the skin surface, muscles and blood vessels; and (4) indirect effects of noise and local vibration on peripheral circulation mediated by the sympathetic nervous system. The pathophysiology of decreased digital circulation may be exaggerated vasoconstriction, organic changes in the digital vessels themselves, or a combination of both. These changes can be induced by chronic exposure to vibration, usually on an occupational basis ${ }^{12,23)}$.

Our results showed that from the 5 th to the 10 th min following the cold immersion test the mean values of deep FBF in those with VWF were significantly lower than their control subjects. The dense innervation of the deeply located vesseles ${ }^{25,26)}$ suggests that they may be more severely affected of the blood vessels by dysfunction of the peripheral nervous system, which must clearly be an inevitable consequence of the vascular changes in the chain saw operators with finger blanching. In the present study, the theory of defective function of the deeply located vessels in those with VWF and numbness was further evaluated, as the finding of severely decreased resting blood flow and the very slow rewarming after direct cooling suggest such a defect. On the basis of the results obtained for FBF, and compared to the FST values, measurements of capillary and deep FBF during the recovery period could expeditiously detect differences in the vascular capacity of those with VWF and the symptom-free workers. This might be due to the fact that during the recovery time, FST has generally less pronounced increase and it requires somehow more prolonged recovery time compared with FBF. It should be noted that the overlap in flow values did not allow separation of the VWF subjects from the controls on an individual basis, which has been a considerable issue in other surveys of FBF among the healthy subjects ${ }^{27)}$ and those with Raynaud's phenomenon ${ }^{10)}$.

The correlation coefficients for linear regression of FST on FBF on each selected conditions (Fig. 3) were significant $(P<0.05$ or 0.01$)$, both for the capillary and deep blood flows. In general, the slope of the regression lines showed that the relationship was steeper for the capillary and was more gradual for the deep FBF. As the capillary FBF might be more affected by the environmental temperature, the correlation coefficient between the FST and the capillary FBF was somehow smaller compared to that of the deep FBF. Hence, we suggest that in the surveys of HAVS, by including the assessment of deep FBF (in addition to the measurement of capillary FBF), more detailed and accurate information on the peripheral circulatory functions of vibration-exposed subjects can be obtained. It was also speculated that evaluation of the dual peripheral circulation may be productive in delineating the pathogenesis of the vibration syndrome.

\section{References}

1) Taylor W, Brammer AJ (1982) Introduction to proceeding of 3rd international conference on handarm vibration. In: Vibration effects on the hand and arm in industry. eds. by Brammer AJ, Taylor W, 1-12, Wiley, New York.

2) Pyykkö I (1974) The prevalence and symptoms of traumatic vasospastic disease among lumberjacks in Finland : a field study. Work Environ Health 11, 11831.

3) Bovenzi M (1988) Finger systolic pressure during local cooling in normal subjects aged 20 to 60 years : reference values for the assessment of digital vasospasm in Raynaud's phenomenon of occupational origin. Int Arch Occup Environ Health 61, 179-81.

4) Olsen N (1988) Diagnostic tests in Raynaud's phenomenon in workers exposed to vibration : a comparative study. Br J Ind Med 45, 426-30.

5) Holloway GA Jr, Watkins DW (1977) Laser Doppler measurement of cutaneous blood flow. J Invest Dermatol 69, 306-9.

6) Öberg PA, Nilsson GE, Tenland T, Holström A, Lewis DH (1979) Use of a new laser Doppler flowmeter for measurement of capillary blood flow in skeletal muscle 
after bullet wounding. Acta Chir Scand Suppl 489, 145 50.

7) Bonner RF, Clem TR, Bowen PD, Bowman RL (1981) Laser-Doppler continuous real-time monitor of pulsatile and mean blood flow in tissue microcirculation. In: Scattering techniques applied to supramolecular and non-equilibrium system. NATO ASI ser B, Vol. 73. eds. by Chen SH, Chu B, Nossal R, 685-702, Plenum, New York.

8) Hirata K, Nagasaka T, Noda Y (1988) Partitional measurement of capillary and arteriovenous anastomostic blood flow in the human finger by laserDoppler-flowmeter. Eur J Appl Physiol 57, 616-21.

9) Hashizume T, Mitsui K (1988) Properties of laser blood flowmeter. Jpn Laser Assoc J 9, 3-7 (in Japanese).

10) Coffman JD, Cohen AS (1971) Total and capillary fingertip blood flow in Raynaud's phenomenon. N Engl J Med 285, 259-63.

11) Welsh CL (1980) The effect of vibration on digital blood flow. Br J Surg 67, 708-10.

12) Hyvarinen J, Pyykkö I, Sundberg S (1973) Vibration frequencies and amplitudes in the aetiology of traumatic vasospastic disease. Lancet I (no. 7807), 791-4.

13) Olsen N, Petring OU (1988) Vibration elicited vasoconstrictor reflex in Raynaud's phenomena. $\mathrm{Br} \mathrm{J}$ Ind Med 45, 415-9.

14) Scheffer M, Dupuis H (1989) Effects of combined handarm vibration and cold on skin temperature. Int Arch Occup Environ Health 61, 375-8.

15) Japanese Ministry of Labor (1975) The technique of a special medical examination related to workers handling vibrating tools. Japanese Labor Standards Bureau Notification No. 609 (in Japanese).

16) Gemne G, Pyykkö I, Taylor W, Pelmear PL (1987) The Stockholm Workshop scale for the classification of coldinduced Raynaud's phenomenon in the hand-arm vibration syndrome (revision of the Taylor-Pelmear scale). Scand J Work Environ Health 13, 275-8.

17) Brammer AJ, Taylor W, Lundborg G (1987) Sensorineural stages of the hand-arm vibration syndrome. Scand J Work Environ Health 13, 279-83.

18) Griffin $M(1990)$ Handbook of human vibration. 5735 , Academic, London.

19) Kirk RE (1982) Experimental design : procedures for the behavioral sciences. 2nd ed. 90-133 (multiple comparison tests), Brooks/Cole, California.

20) Coffman JD (1972) Total and nutritional blood flow in the finger. Clin Sci 42, 243-50.

21) Coffman JD (1994) Effects of endothelium-derived nitric oxide on skin and digital blood flow in humans. Am J Physiol 267, H2087-90.

22) Okada A, Yamashita $T$, Nagono $C$, Ikeda $T$, Yachi $A$, Shibata S (1971) Studies on the diagnosis and pathogenesis of Raynaud's phenomenon of occupational origin. Br J Ind Med 28, 353-7.

23) James PB, Galloway RW (1975) Arteriography of the hand in men exposed to vibration. In: Vibration white finger in industry. eds. by Taylor W, Pelmear PL, 3142, Academic, London.

24) Mirbod SM, Yoshida H, Komura Y, Fujita S, Nagata C, Miyashita K, Inaba R, Iwata H (1994) Prevalence of Raynaud's phenomenon in different groups of workers operationg hand-held vibrating tools. Int Arch Occup Environ Health 66, 13-22.

25) Abrahamson DI (1965) Pathophysiology of arteriovenous shunts in the extremities. J Cardiovasc Surg 217, 217-30.

26) Hales JRS, Molyneux GS (1988) Control of cutaneous arteriovenous anastomoses. In: Vascular smooth muscle, peptides, autonomic nerves and endothelium. ed. by Vanhoutte PM, 321-2, Raven, New York.

27) Bovenzi M, Griffin MJ, Ruffell CM (1995) Vascular responses to acute vibration in the fingers of normal subjects. Cent Eur J Public Health 3 (suppl), 15-18. 